\title{
The initial success rate of cardiopulmonary resuscitation and its associated factors in patients with cardiac arrest within 24 hours after anesthesia for an emergency surgery
}

\author{
This article was published in the following Dove Press journal: \\ Risk Management and Healthcare Policy \\ 21 March 2014 \\ Number of times this article has been viewed
}

\author{
Visith Siriphuwanun' \\ Yodying Punjasawadwong' \\ Worawut Lapisatepun' \\ Somrat Charuluxananan ${ }^{2}$ \\ Ketchada Uerpairojkit ${ }^{2}$ \\ Jayanton Patumanond ${ }^{3}$ \\ 'Department of Anesthesiology, \\ Faculty of Medicine, Chiang Mai \\ University, Chiang Mai, Thailand; \\ ${ }^{2}$ Department of Anesthesiology, \\ Faculty of Medicine, Chulalongkorn \\ University, Bangkok, Thailand; \\ ${ }^{3}$ Department of Community Medicine, \\ Faculty of Medicine, Chiang Mai \\ University, Chiang Mai, Thailand
}

\begin{abstract}
Purpose: To determine the initial success rate and its associated factors on cardiopulmonary resuscitation (CPR) in patients with cardiac arrest within 24 hours after receiving anesthesia for an emergency surgery.
\end{abstract}

Patients and methods: After the hospital ethical committee gave approval for this study, the anesthesia providers recorded all relevant data regarding CPR in patients with cardiac arrest within 24 hours after anesthesia for emergency surgery at Maharaj Nakorn Chiang Mai Hospital, a university hospital in Northern Thailand. Only data from the cardiac arrest patients who received the first CPR attempt were included in the analysis. The end point of the initial success of CPR was return of spontaneous circulation (ROSC). Factors related to ROSC were determined by univariate analyses and multiple logistic regression analysis. The odds ratios (OR) and 95\% confidence intervals (CI) were used to calculate the strength of the factors associated with the ROSC.

Results: Of the 96 cardiac arrest patients, 44 patients (45.8\%) achieved ROSC. Factors associated with ROSC were electrocardiogram monitoring for detected cardiac arrest $(\mathrm{OR}=4.03 ; 95 \%$ $\mathrm{CI}=1.16-14.01 ; P=0.029)$, non-shock patients before arrest $(\mathrm{OR}=8.54 ; 95 \% \mathrm{CI}=2.13-34.32$; $P=0.003)$, timing to response of activated CPR team within 1 minute ( $\mathrm{OR}=9.37 ; 95 \%$ $\mathrm{CI}=2.55-34.39 ; P<0.001)$, having trained $\mathrm{CPR}$ teams $(\mathrm{OR}=8.76 ; 95 \% \mathrm{CI}=2.50-30.72$; $P<0.001$ ), and administration of more than one dose of epinephrine (OR $=5.62 ; 95 \%$ $\mathrm{CI}=1.32-23.88 ; P<0.019)$.

Conclusion: Patients undergoing anesthesia for an emergency surgery are at risk for perioperative cardiac arrest with high mortality which requires immediate CPR. Our results have confirmed that early detection of cardiac arrest by vigilant electrocardiogram monitoring and prompt management with a qualified team are important factors in improving the success of CPR. Emergency surgical patients at risk for cardiac arrest should be promptly managed, with facilities available not only during the operation but also during the pre- to postoperative period.

Keywords: initial successful CPR, CPR, ROSC, general anesthesia

\section{Introduction}

Emergency surgery is, by definition, an unplanned surgical procedure with limited preoperative preparation. It can lead to an increased risk of perioperative morbidity and mortality. The risk of cardiac arrest in emergency surgery has been shown to be 3-11 times higher than elective cases and also has higher mortality rates. ${ }^{1-5}$ A study in Newland, USA, reported that $60 \%$ of all episodes of cardiac arrest in surgical patients occurred in patients undergoing emergency surgeries. ${ }^{6}$ In developing countries,
Correspondence: Yodying

Punjasawadwong

Department of Anesthesiology,

Faculty of Medicine, Chiang Mai

University, Chiang Mai, Thailand

Tel +66 53945524

Fax +6653945526

Email typunja@gmail.com 
the incidence of perioperative cardiac arrest varies from 6.53 per 10,000 to 40.4 per $10,000 .^{3,7,8}$

Cardiopulmonary resuscitation (CPR) is defined as "artificial respiration, cardiac compressions, administration of resuscitation medications, and electrical defibrillation in order to increase oxygenation of tissues in the body for protecting brain death, preserving circulation, and delivering oxygen to vital organs such as brain and heart." 9 The prognostic factors predicting outcomes in cardiac arrest patients may include patient location at the time of CPR, underlying medical problems, American Society of Anesthesiologists (ASA) class, initial electrocardiogram (EKG) rhythm, hemodynamic changes, blood loss, blood replacement, and anatomic site of the operation. ${ }^{4,10-18}$ From previous studies, many factors such as short time intervals from detecting cardiac arrest to the time of actually starting CPR, early defibrillation, and effective advanced cardiac life support (ACLS) were determinants in the success of CPR, ${ }^{9}$ which generally is regarded as the return of spontaneous circulation (ROSC) as the initial end point. However, few studies have focused on the effectiveness of CPR in cardiac arrest patients during and immediately after emergency surgery. Therefore, this study was conducted to determine the initial success rate and identify factors associated with the success of CPR in patients whose cardiac arrest occurred within 24 hours after receiving anesthesia for emergency surgery at Maharaj Nakorn Chiang Mai Hospital, a university-based teaching hospital in Northern Thailand.

\section{Patients and methods}

After the hospital ethical committee of the Faculty of Medicine, Chiang Mai University, Thailand gave approval for this study, the data from patients who had cardiac arrest within 24 hours after receiving general anesthesia for emergency surgery at Maharaj Nakorn Chiang Mai Hospital, a university hospital in Northern Thailand, were prospectively collected during a period from October 1, 2010 to September 31, 2011. Only data from the cardiac arrest patients who received the first CPR attempt were included in the analysis. Data of those who had received CPR prior to surgery or had subsequent CPR were excluded.

During the study period, the anesthesia providers recorded all relevant data from patients undergoing general anesthesia for emergency surgery using the anesthesiology data collection form (Figure S1). The data included patient characteristics (age and sex), pre-anesthetic comorbidities, preoperative medical conditions, ASA physical status classification, anatomic site of operation, patient monitoring, anesthetic technique, airway management, administration of anesthesia, and anesthetic agents used. The anesthesia techniques depended on the discretion of the attending anesthesiologists. The patients' clinical courses were documented from the start of anesthesia until 24 hours after the end of the operation. All preplanned data regarding CPR in those who had cardiac arrest were recorded on the data collection form for cardiac arrest events (Figure S2). The form had been developed and tested in ten cases of cardiac arrest patients before commencement of the study. The researcher and the research assistants were trained and standardized to collect the data and perform internal data audits. The research assistants followed up the post-cardiac arrest patients for 24 hours and completed the anesthesia record to document outcomes. The completed data were obtained by chart review, anesthesiology records, medical records, EKG, laboratory reports, and observations made after the CPR event. Two independent senior anesthesiologists and surgeons reviewed all events and resolved any discrepancies by discussion. All of the relevant data were checked and corrected for inconsistencies before entering onto computer by using the double-entry technique for further analyses.

The main outcomes of initial successful CPR measurements in this study were ROSC and factors associated with ROSC. Outcome definitions were as follows: ROSC was the resumption of sustained perfusion and cardiac activity correlated with respiratory attempt after cardiac arrest, and the patients to have vital signs including pulse and blood pressure; mortality (non-ROSC) was defined as an initial death during CPR, related to either anesthesia or other causes; and successful performance of CPR was defined as effective actions of the CPR team in the management of resuscitation, including appropriate drugs given resulting in a beneficial outcome for the patient within 20 minutes after initiation of CPR.

The statistical analysis was performed using the STATA (StataCorp LP, College Station, TX, USA) statistical package. Descriptive statistics were used to describe the distribution of the resuscitated patients according to their age, sex, ASA physical status, and their comorbidities. The data were expressed as means and standard deviations for continuous data and as a percentage for categorical data. The end point of the initial success of CPR was ROSC and presented as a percentage along with 95\% confidence intervals (CIs). Factors related to the success of ROSC were firstly determined by univariate analyses. Factors statistically associated with the success of ROSC at $P$-values of less than 0.02 were selected for further analysis by multiple logistic regression analysis. A $P$-value of less than 0.05 was 
considered statistically significant. The odds ratio (OR) and 95\% CI were used to summarize the strength of the factors associated with the initial success of CPR.

\section{Results \\ General results}

During the study period, the total number of emergency surgery patients recorded was 7,145 , of whom $1.34 \%$ suffered cardiac arrest in our center. Included in this group were 96 patients who underwent CPR following cardiac arrest within 24 hours after receiving anesthesia for emergency surgery. The majority of them (68.7\%) were male. Their ages varied from 18 days to 84 years old, with an average age of $42.19 \pm 24.43$ years. Most of the patients had an ASA physical status class of 4-5, which was twice as common as ASA class $2-3(66.7 \%$ versus $33.3 \%$ ) (data not shown). The patient comorbidities included respiratory $(80.2 \%)$, cardiovascular (71.9\%), neuromuscular (38.5\%), hematologic $(65.6 \%)$, and endocrine disorders $(21.9 \%)$. Regarding anatomic sites of the operation, abdominal site was two times more common than an intracranial site (53.1\% versus $21.9 \%$ ). The other sites were cardiac and intrathoracic, with percentages of $6.3 \%$ and $14.6 \%$, respectively; the average time in surgery was $2.6 \pm 1.9$ hours. Nearly half $(46.0 \%)$ of the cardiac arrest events occurred in the operating theater, and about two-thirds (62.5\%) occurred during evening or nighttime shifts. About $59.4 \%$ of the cardiac arrest events were detected by a member of the anesthesiology team, while $40.6 \%$ by those in the ward team. Cardiac arrest was related to cardiovascular events (86.5\%), six times more often than respiratory events (13.5\%). Greater than half $(56.3 \%)$ of the cardiac arrest events were detected by EKG monitoring, while $43.5 \%$ were detected by clinical signs (absence of pulse on palpation) (data not shown). Regarding the initial EKG rhythm, asystole was the most common (63.5\%), followed by ventricular fibrillation/ventricular tachycardia (13.5\%), pulseless electrical activity (13.5\%), bradycardia (6.3\%), and tachycardia (3.2\%). The main cause of cardiac arrest was attributed to patients' causes (90.6\%), followed by surgical causes $(4.2 \%)$. The most common hemodynamic changes before arrest were severe hypotension (60.4\%) and cardiac arrhythmias (11.5\%). Most patients were intubated and received mechanical ventilation and vasoactive drugs before the cardiac arrest (data not shown).

\section{Initial success of CPR and associated factors}

The end point of initial resuscitation success in this study was ROSC, as shown in Figure 1. Forty-four patients

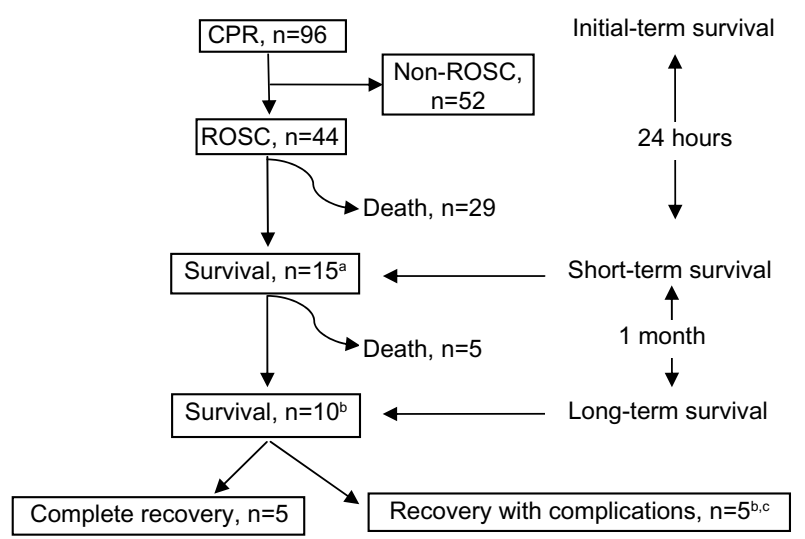

Figure I CPR performance and outcomes.

Notes: ${ }^{a}>24$ hours -7 days hospital unit admission: ICU $(n=10)$, ward $(n=4)$, and hospital discharge $(n=1)$; ${ }^{b}>7$ days -1 month unit admission: ICU $(n=2)$, ward $(n=7)$, hospital discharge with complete recovery $(n=4)$, and hospital discharge with complications $(n=4)$; $c$-month complications: death $(n=1)$, respiratory $(n=1)$, cardiovascular $(n=2)$, neurological $(n=1)$, hematology/infection $(n=2)$, renal impairment $(n=2)$, and endocrine/metabolic $(n=2)$.

Abbreviations: CPR, cardiopulmonary resuscitation; ICU, intensive care unit; ROSC, return of spontaneous circulation.

(45.8\%) experienced an ROSC. According to analysis, the characteristics in ROSC patients did not differ from the nonROSC patients (Table 1); and according to univariate analysis, ROSC was related to hemodynamic changes, location at the time of cardiac arrest, the CPR team's management, administration of epinephrine, etc, as shown in Table 2.

Analysis according to multivariable logistic regression revealed that cardiac arrest detected by EKG monitoring was four times more likely to result in ROSC than cardiac arrest detected by pulse palpation ( $\mathrm{OR}=4.03 ; 95 \% \mathrm{CI}=1.16-14.01$; $P=0.029)$; lack of shock resulted in ROSC eight times more often than the presence of shock (OR $=8.54 ; 95 \% \mathrm{CI}=2.13$ 34.32; $P=0.003$ ); rapid response to activated CPR teams (within 1 minute) was nine times more likely to result in ROSC (OR $=9.37$; 95\% CI $=2.55-34.39 ; P<0.001$ ); having trained CPR team members increased the likelihood of ROSC ( $\mathrm{OR}=8.76 ; 95 \% \mathrm{CI}=2.50-30.72 ; P<0.001)$; and administering more than one dose of epinephrine increased ROSC $(\mathrm{OR}=5.62 ; 95 \% \mathrm{CI}=1.32-23.88 ; P<0.019)$ (Table 3).

\section{Discussion}

Our research was conducted at a teaching university hospital in Northern Thailand, where it was reported that, annually, the incidence of cardiac arrest in emergency surgical patients was 14-fold higher than that found in elective surgical cases (115.66 per 10,000 versus 8.14 per 10,000). ${ }^{19}$ During the study period, the total number of cases of emergency surgical patients recorded was 7,145, of whom $1.34 \%$ were found to experience cardiac arrest. The incidence was 
Table I Patient characteristics in the ROSC and non-ROSC groups

\begin{tabular}{|c|c|c|c|}
\hline Characteristic & $\begin{array}{l}\text { ROSC } \\
n(\%), n=44\end{array}$ & $\begin{array}{l}\text { Non-ROSC } \\
n(\%), n=52\end{array}$ & $P$-value \\
\hline Sex & & & 0.581 \\
\hline Male & $29(65.9)$ & $37(7 \mathrm{I} .1)$ & \\
\hline Female & $15(34.1)$ & $15(28.9)$ & \\
\hline Age (years) & & & 0.341 \\
\hline$\leq 8$ & 7 (I5.9) & $6(11.5)$ & \\
\hline $9-60$ & $28(63.6)$ & $31(59.6)$ & \\
\hline$>60$ & $9(20.5)$ & $15(28.9)$ & \\
\hline Mean \pm SD & $39.7 \pm 22.9$ & $44.3 \pm 25.6$ & \\
\hline ASA physical status & & & 0.428 \\
\hline 2 & $5(11.4)$ & $2(3.9)$ & \\
\hline 3 & $10(22.7)$ & $15(28.8)$ & \\
\hline 4 & $12(27.3)$ & $21(40.4)$ & \\
\hline 5 & $17(38.6)$ & $14(26.9)$ & \\
\hline \multicolumn{4}{|l|}{ Anatomic site of surgery } \\
\hline Intracranial & $8(18.2)$ & $13(25.0)$ & 0.421 \\
\hline Intra-abdominal & $25(56.7)$ & $26(50.0)$ & 0.399 \\
\hline Intrathoracic & $4(9.1)$ & $2(3.9)$ & 0.227 \\
\hline Cardiac & $5(11.4)$ & $9(17.2)$ & 0.886 \\
\hline Others & $2(4.6)$ & $2(3.9)$ & 0.658 \\
\hline \multicolumn{4}{|c|}{ Preoperative comorbidity ${ }^{\mathrm{a}}$} \\
\hline Respiratory & $35(79.5)$ & $42(80.8)$ & 0.881 \\
\hline Cardiovascular & $33(75.0)$ & $36(69.2)$ & 0.533 \\
\hline Neuromuscular & $17(38.6)$ & $20(38.5)$ & 0.986 \\
\hline Hematological & $28(63.6)$ & $35(67.3)$ & 0.707 \\
\hline Endocrine & $9(20.0)$ & $12(23.1)$ & 0.758 \\
\hline Others & $22(50.0)$ & $29(55.8)$ & 0.575 \\
\hline $\begin{array}{l}\text { Estimate blood loss } \\
(\mathrm{mL}), \text { mean } \pm S D\end{array}$ & $1917.5 \pm 2112.4$ & $1455.7 \pm 1786.5$ & 0.419 \\
\hline $\begin{array}{l}\text { Total volume } \\
\text { replacement }(\mathrm{mL}) \text {, } \\
\text { mean } \pm \mathrm{SD}\end{array}$ & $6895.0 \pm 6284.3$ & $6706.0 \pm 6574.5$ & 0.472 \\
\hline $\begin{array}{l}\text { Blood replacement }(\mathrm{mL}) \\
\text { mean } \pm \text { SD }\end{array}$ & $|58| .7 \pm|49| .8$ & $|423.0 \pm| 440.4$ & 0.459 \\
\hline $\begin{array}{l}\text { Timing of cardiac arrest } \\
\text { from surgery (minutes), } \\
\text { mean } \pm S D\end{array}$ & $181.6 \pm 326.3$ & $495.1 \pm 409.7$ & 0.001 \\
\hline $\begin{array}{l}\text { Duration time of CPR } \\
\text { (minutes), mean } \pm S D\end{array}$ & $21.5 \pm 18.9$ & $26.1 \pm 25.8$ & 0.168 \\
\hline
\end{tabular}

Note: ane patient had more than one comorbidity.

Abbreviations: ASA, American Society of Anesthesiologists; CPR, cardiopulmonary resuscitation; ROSC, return of spontaneous circulation; SD, standard deviation.

higher than that occurring in four other teaching hospitals in Thailand, which reported the incidence of perioperative cardiac arrest ranging from 8.20 to 44.31 per $10,000.3,8,20,21$ Comparing results with other findings of perioperative cardiac arrest in elective surgery, emergency surgery in our hospital had higher cardiac arrest rates than four studies held in developed countries (1.1-50.0 per 10,000). ${ }^{2,22-24}$ Compared with results from both critical care units and a general ward, our rate of cardiac arrest was eight times higher than the result shown in two reports from a developed country. ${ }^{25,26}$
There were many factors contributing to the higher incidence of cardiac arrest in our studies. The patients in our study group were severely ill, with the majority of emergency surgery cases related to trauma (63.5\%). Many of the patients $(80.4 \%)$ were directly transferred from the emergency room for unplanned surgery. Most of the patients underwent abdominal surgery (53.1\%). In those undergoing abdominal surgery, three out of four cases were due to abdominal trauma (36/51 cases; $70.5 \%$ ) presenting with shock before cardiac arrest. More than half of the cardiac arrest patients had severe ASA physical status (ASA class 4 and 5), with major problems of the respiratory and cardiovascular systems. Moreover, the majority of patients had cardiovascular instability, which had not been managed properly due to the need for emergency surgery. Hence, CPR in those vulnerable patients presented a big challenge to the resuscitators.

We found ROSC occurring in nearly half of the resuscitated patients. Comparing with studies in developed countries, this rate was similar to two studies, one in Spain and the other in Plymouth (UK), ${ }^{27,28}$ but lower than the ROSC reported in Italy. ${ }^{24} \mathrm{~A}$ study in France found that ROSC was half of the rate in our study. ${ }^{29}$ The rate of ROSC in our study corresponded with the result from three other studies carried out in nonsurgical cases at university-based teaching hospitals elsewhere in Thailand, which reported the incidences varying from $37.5 \%$ to $61.7 \%$., 3,12 The majority of nonsurgical cases had medical problems. By contrast, our study investigated cardiac arrest due to underlying surgical conditions (such as bleeding, hypovolemia, and coagulation). ${ }^{5,23,30} \mathrm{We}$ found nearly $85 \%$ of the cardiac arrest patients underwent intra-abdominal surgery. The majority of the cardiac arrest patients $(72 \%)$ needed blood transfusions of greater than $1,000 \mathrm{~mL}$ and fluid administration of greater than 2,000 mL. In addition, we found respiratory diseases and cardiovascular diseases as major comorbidities. Hence, despite successful initial CPR, only $10 \%$ survived at 1 month, and only $5 \%$ survived without complications. This factor highlights that the intensive care unit or ward teams should provide more appropriate post-resuscitation care.

The relatively high mortality rate, despite initial successful resuscitation, indicates the requirement of improvement in our perioperative management, not only in the intraoperative period but also the pre- and postoperative periods. Further studies regarding the outcome of "fast track" emergency surgery in our hospital should be conducted, particularly for high-risk emergency patients.

The statistically significant factors associated with the initial ROSC were EKG-detected cardiac arrest, cardiac 
Table 2 Univariate logistic analysis of factors related with ROSC in patients with cardiac arrest within 24 hours after anesthesia for an emergency surgery

\begin{tabular}{|c|c|c|c|c|c|}
\hline Factor & $\begin{array}{l}\text { ROSC } \\
n(\%) n=44\end{array}$ & $\begin{array}{l}\text { Non-ROSC } \\
n(\%) n=52\end{array}$ & OR & $95 \% \mathrm{Cl}$ & $P$-value \\
\hline \multicolumn{6}{|c|}{ Intensive monitoring before cardiac arrest ${ }^{\mathrm{a}}$} \\
\hline No & $9(20.4)$ & II (2I.2) & 1.00 & $0.21-|.3|$ & 0.155 \\
\hline Yes & $35(79.6)$ & $41(78.8)$ & 0.52 & & \\
\hline \multicolumn{6}{|l|}{ Location at time of cardiac arrest } \\
\hline Outside the operating room ${ }^{\mathrm{b}}$ & II (25.0) & $40(76.9)$ & 1.00 & $3.98-33.11$ & $<0.001$ \\
\hline In the operating room & $33(75.0)$ & $12(23.1)$ & 11.03 & & \\
\hline \multicolumn{6}{|l|}{ Signs/symptoms indicating arrest } \\
\hline Pulseless (palpation) & $12(27.3)$ & $30(57.7)$ & 1.00 & $1.42-9.49$ & 0.002 \\
\hline Monitor EKG for indicating arrest & $32(72.7)$ & $22(42.3)$ & 3.36 & & \\
\hline \multicolumn{6}{|l|}{ Initial EKG rhythm } \\
\hline Non-shockable rhythm & $32(72.3)$ & $5 I(98.1)$ & 1.00 & $2.00-182.86$ & $<0.001$ \\
\hline Shockable rhythm ${ }^{d}$ & $12(27.3)$ & I (I.9) & 19.13 & & \\
\hline \multicolumn{6}{|l|}{ Shock patients before cardiac arrest } \\
\hline Yes & $20(45.4)$ & $38(73.1)$ & 1.00 & $1.28-8.38$ & 0.006 \\
\hline No & $24(54.6)$ & $14(26.9)$ & 3.26 & & \\
\hline \multicolumn{6}{|c|}{ Timing to response of activated CPR teams } \\
\hline$>I$ minute & II (25.0) & $40(76.9)$ & 1.00 & $3.57-28.58$ & $<0.001$ \\
\hline$\leq \mathrm{I}$ minute & $33(75.0)$ & $12(23.1)$ & 10.0 & & \\
\hline \multicolumn{6}{|l|}{ CPR teams } \\
\hline Ward teams & $9(20.4)$ & $30(57.7)$ & 1.00 & $1.96-14.98$ & $<0.001$ \\
\hline Anesthetic teams & $35(79.6)$ & $22(42.3)$ & 5.30 & & \\
\hline \multicolumn{6}{|l|}{ All CPR team members trained ${ }^{e}$} \\
\hline No & II (25.0) & $38(73.1)$ & 1.00 & $2.98-22.68$ & $<0.001$ \\
\hline Yes & $33(75.0)$ & $14(26.9)$ & 8.14 & & \\
\hline \multicolumn{6}{|l|}{ Administration of epinephrine } \\
\hline$<2$ doses & $8(18.2)$ & $26(50.0)$ & 1.00 & $1.60-12.24$ & 0.001 \\
\hline$\geq 2$ doses & $36(81.8)$ & $26(50.0)$ & 4.5 & & \\
\hline
\end{tabular}

Notes: antensive monitoring included EKG, pulse oximetry, capnograph monitoring, and invasive cardiovascular monitoring/arterial blood testing. Non-intensive monitoring included EKG, noninvasive blood pressure, and pulse oximetry; 'brecovery room, intensive care unit, ward, X-ray, and magnetic resonance imaging; 'asystole, pulseless

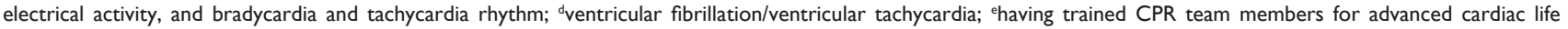
support techniques from the program in CPR at Maharaj Nakorn Chiang Mai Hospital. Boldface indicates univariate logistic factors related with ROSC.

Abbreviations: $\mathrm{Cl}$, confidence interval; CPR, cardiopulmonary resuscitation; EKG, electrocardiogram; OR, odds ratio; ROSC, return of spontaneous circulation.

arrest in those without shock, response time of activated CPR teams within 1 minute, a well-trained CPR team, and administration of epinephrine. From our study, cardiac arrest detected by monitor was five times more likely to result in ROSC than that detected by absence of a pulse on palpation.

Table 3 Multivariate logistic regression analysis of factors related to ROSC

\begin{tabular}{|c|c|c|c|}
\hline Associated factor & $\begin{array}{l}\text { Adjusted } \\
\text { OR }\end{array}$ & $95 \% \mathrm{Cl}$ & $P$-value \\
\hline $\begin{array}{l}\text { EKG monitor for detected } \\
\text { cardiac arrest }\end{array}$ & 4.03 & $1.16-14.01$ & 0.029 \\
\hline Non-shock patients before arrest & 8.54 & $2.13-34.32$ & 0.003 \\
\hline $\begin{array}{l}\text { Timing to response of activated } \\
\text { CPR team within I minute }\end{array}$ & 9.37 & $2.55-34.39$ & 0.001 \\
\hline All CPR team members trained & 8.76 & $2.50-30.72$ & 0.001 \\
\hline $\begin{array}{l}\text { Administration of more than } \\
\text { one dose of epinephrine }\end{array}$ & 5.62 & $1.32-23.88$ & 0.019 \\
\hline
\end{tabular}

Abbreviations: $\mathrm{Cl}$, confidence interval; $\mathrm{CPR}$, cardiopulmonary resuscitation; EKG, electrocardiogram; OR, odds ratio; ROSC, return of spontaneous circulation.
This was demonstrated by the better outcomes in locations where the patient was closely monitored. ${ }^{4,31}$ It appears that teams should be vigilant in order to detect cardiac arrest by means of monitoring rather than relying on palpation alone. We also found that a higher rate of ROSC occurred in the operating theater. The operating room has plentiful monitoring facilities, including EKG, pulse oximetry, capnograph monitoring, defibrillator, invasive cardiovascular monitoring, and arterial blood testing, which provide earlier detection and prompt treatment of cardiac arrest more effectively than in the ward.

In our study, patients who were hemodynamically unstable and presented with signs of shock had lower ROSC rates than those without these conditions. According to other studies, the negative outcomes are primarily related to the condition of the cardiovascular system before arrest. $13,15,17,32$ Three reports found that shock and unstable hemodynamic changes decrease the ROSC rate. ${ }^{1,3,14}$ 
Quick response of the CPR teams, defined as initiating CPR within 1 minute, resulted in higher rates of ROSC. This result confirms the findings of previous studies, conducted in a developed country, which reported that the arrival of the CPR team within a short time frame results in a greater survival rate. ${ }^{31}$ One result from a developing-country study found that early CPR increases the survival rate. ${ }^{4}$ Correspondingly, our study found that the time to response of activated CPR teams within 1 minute was 9-fold higher in ROSC than the response time after 1 minute. There has been a report showing that the onset time to start CPR within 1 minute increases survival. ${ }^{32}$ Two studies in Thailand demonstrated that starting basic life support within 1 minute results in $83.1 \%-86.7 \%$ survival rates. ${ }^{4,12}$ Therefore, our result confirms that we should establish the goal of onset time to activate the CPR team to start CPR within 1 minute of the arrest. CPR 2010 recommendations include early CPR to improve CPR outcomes. ${ }^{9,16,30}$ The results suggest that our current system should be developed with a strategy to achieve a shorter response time to initiate CPR. Furthermore, that the resuscitation drug, epinephrine, is available for use, as ACLS protocol guidelines 2010 recommend that administration of epinephrine during CPR with shockable EKG rhythm improves myocardial and cerebral blood flow as well as survival in cardiac arrest. ${ }^{9}$

Another significant factor associated with ROSC in our study was the quality of the CPR teams. Many reports show that factors correlating to successful CPR during surgery are individual knowledge, skills, and training practice. ${ }^{1,32,33}$ A study in the developing country Thailand ${ }^{4}$ showed that factors significantly relating to successful CPR include team training. The availability of anesthesia providers, who have been well trained and continuously updated in the techniques of advanced cardiac life support, would result in a more successful resuscitation outcome. Our finding supports the program of continual updating of and ongoing training in CPR techniques. This conclusion was confirmed with the result of a recent study in which ROSC was more likely if the CPR was performed under the supervision of trained resuscitators and experienced teams such as anesthesiologists and intensive care unit/operating room teams.

It should be noted that our study has some limitations. The data of time activated CPR teams and start times of CPR variables recorded may not be accurate in some cases, because of data collection from various patient care areas, particularly where the researchers may have lacked complete data which had not been fully recorded due to lack of cooperation. Additionally, staff and patient numbers differed during the period of time that cardiac arrest occurred. Moreover, the study design was limited due to the small sample size, and the analysis was not adjusted for certain unknown factors. However, the strength of our study lies in the fact that we studied many different areas, which means the results of this study could be applied in many different settings.

\section{Conclusion}

Patients undergoing anesthesia for emergency surgery are at risk of perioperative cardiac arrest with high mortality rates which require immediate $\mathrm{CPR}$. Our results have confirmed that early detection of cardiac arrest by vigilant EKG monitoring and prompt management with a qualified team are important factors in improving the success of CPR. Emergency surgical patients at risk for cardiac arrest should be promptly managed, with facilities available not only during the operation but also during the pre- to postoperative period.

\section{Acknowledgments}

This study has been supported by a grant from the Faculty of Medicine, Maharaj Nakorn Chiang Mai Hospital, Chiang Mai University. The authors thank the director of Maharaj Nakorn Chiang Mai Hospital, the team's advisor, and the Department of Anesthesiology for the use of the data.

\section{Disclosure}

The authors report no conflicts of interest in this work.

\section{References}

1. Zuercher M, Ummenhofer W. Cardiac arrest during anesthesia. Curr Opin Crit Care. 2008;14:269-274.

2. Braz LG, Módolo NS, do Nascimento P Jr, et al. Perioperative cardiac arrest: a study of 53,718 anaesthetics over $9 \mathrm{yr}$ from a Brazilian teaching hospital. Br J Anaesth. 2006;96:569-575.

3. Tamdee D, Charuluxananan S, Punjasawadwong Y, et al. Factors related to 24-hour perioperative cardiac arrest in geriatric patients in a Thai university hospital. J Med Assoc Thai. 2009;92:198-207.

4. Suraseranivongse S, Chawaruechai T, Saengsung P, Komoltri C. Outcome of cardiopulmonary resuscitation in a 2,300-bed hospital in a developing country. Resuscitation. 2006;71:188-193.

5. Wallmuller C, Meron G, Kurkciyan I, Schober A, Stratil P, Sterz F. Causes of in-hospital cardiac arrest and influence on outcome. Resuscitation. 2012;83:1206-1211.

6. Newland MC, Ellis SJ, Lydiatt CA, et al. Anesthetic-related cardiac arrest and its mortality: a report covering 72,959 anesthetics over 10 years from a US teaching hospital. Anesthesiology. 2002;97:108-115.

7. Ahmed A, Ali M, Khan M, Khan F. Perioperative cardiac arrests in children at a university teaching hospital of a developing country over 15 years. Paediatr Anaesth. 2009;19:581-586.

8. Charuluxananan S, Suraseranivongse S, Jantorn P, et al. Multicentered study of model of anesthesia related adverse events in Thailand by incident report (The Thai Anesthesia Incidents Monitoring Study): results. J Med Assoc Thai. 2008;91:1011-1019. 
9. Dabrowska A, Telec W. [New guidelines of Basic and Advanced Cardiopulmonary Resuscitation and Emergency Cardiovascular Care (ECC) American Heart Association (AHA)]. Wiad Lek. 2010;64: 127-131. Polish.

10. Rodanant O, Hintong T, Chua-in W, Tanudsintum S, Sirinanmd C, Kyokong O. The Thai anesthesia incidents study (THAI Study) of perioperative death in geriatric patients. J Med Assoc Thai. 2007;90: 1375-1381.

11. Pembeci K, Yildirim A, Turan E, et al. Assessment of the success of cardiopulmonary resuscitation attempts performed in a Turkish university hospital. Resuscitation. 2006;68:221-229.

12. Krittayaphong R, Saengsung P, Chawaruechai T, Yindeengam A, Udompunturak S. Factors predicting outcome of cardiopulmonary resuscitation in a developing country: the Siriraj cardiopulmonary resuscitation registry. J Med Assoc Thai. 2009;92:618-623.

13. Olotu A, Ndiritu M, Ismael M, et al. Characteristics and outcome of cardiopulmonary resuscitation in hospitalised African children. Resuscitation. 2009;80:69-72.

14. Haque A, Rizvi A, Bano S. Outcome of in-hospital pediatric cardiopulmonary arrest from a single center in Pakistan. Indian $J$ Pediatr. 2011;78:1356-1360.

15. Saghafinia M, Motamedi MH, Piryaie M, et al. Survival after inhospital cardiopulmonary resuscitation in a major referral center. Saudi J Anaesth. 2010;4:68-71.

16. Bradley SM. Update in cardiopulmonary resuscitation. Minerva Cardioangiol. 2011;59:239-253.

17. Lundy DJ, Ross SE, Schorr C, Jones AE, Trzeciak S. Outcomes of trauma victims with cardiac arrest who survive to intensive care unit admission. J Trauma. 2011;71:12-16.

18. Xanthos T, Karatzas T, Stroumpoulis K, et al. Continuous chest compressions improve survival and neurologic outcome in a swine model of prolonged ventricular fibrillation. Am J Emerg Med. 2012;30: 1389-1394.

19. Department of Anesthesiology, Faculty of Medicine, Chiang Mai University. Annual Statistical Service Report. 2011:32-45.

20. Aroonpruksakul N, Raksakiatisak M, Thapenthai Y, et al. Perioperative cardiac arrest at Siriraj Hospital between 1999-2001. J Med Assoc Thai. 2002;85 Suppl 3:S993-S999.

21. Boonmak P, Boonmak S, Sathitkarnmanee T, Chau-In W, Nonlhaopol D, Thananun M. Surveillance of anesthetic related complications at Srinagarind Hospital, Khon Kaen University, Thailand. J Med Assoc Thai. 2005;88:613-622.
22. An JX, Zhang LM, Sullivan EA, Guo QL, Williams JP. Intraoperative cardiac arrest during anesthesia: a retrospective study of 218,274 anesthetics undergoing non-cardiac surgery. Chin Med J (Engl). 2011;124:227-232.

23. Goswami S, Brady JE, Jordan DA, Li G. Intraoperative cardiac arrests in adults undergoing noncardiac surgery: incidence, risk factors, and survival outcome. Anesthesiology. 2012;117:1018-1026.

24. Sandroni C, Nolan J, Cavallaro F, Antonelli M. In-hospital cardiac arrest: incidence, prognosis and possible measures to improve survival. Intensive Care Med. 2007;33:237-245.

25. Harrington DT, Phillips B, Machan J, et al. Factors associated with survival following blunt chest trauma in older patients: results from a large regional trauma cooperative. Arch Surg. 2010;145:432-437.

26. Lee HK, Lee H, No JM, et al. Factors influencing outcome in patients with cardiac arrest in the ICU. Acta Anaesthesiol Scand. 2013;57: 784-792.

27. Leis CC, Hernandez CC, Blanco MJ, Paterna PC, Hernandez Rde E, Torres EC. Traumatic cardiac arrest: should advanced life support be initiated? J Trauma Acute Care Surg. 2013;74:634-638.

28. Cooper S, Janghorbani M, Cooper G. A decade of in-hospital resuscitation: outcomes and prediction of survival? Resuscitation. 2006;68:231-237.

29. Faucher A, Savary D, Jund J, Carpentier F, Payen JF, Danel V. [Optimize the resuscitation of prehospital cardiac arrest in trauma patients: a prospective register's experience]. Ann Fr Anesth Reanim. 2009;28:442-447. French.

30. Berg MD, Clark LL, Valenzuela TD, Kern KB, Berg RA. Post-shock chest compression delays with automated external defibrillator use Resuscitation. 2005;64:287-291.

31. Sandroni C, Ferro G, Santangelo S, et al. In-hospital cardiac arrest: survival depends mainly on the effectiveness of the emergency response. Resuscitation. 2004;62:291-297.

32. Aune S, Eldh M, Engdahl J, et al. Improvement in the hospital organisation of CPR training and outcome after cardiac arrest in Sweden during a 10-year period. Resuscitation. 2011;82:431-435.

33. Patel MJ, Khan NU, Furqan M, et al. APACHE II scores as predictors of cardio pulmonary resuscitation outcome: evidence from a tertiary care institute in a low-income country. Saudi J Anaesth. 2012;6:31-35. 


\section{Supplementary Material}

Case Report Form

Anesthetic record from (Form 1)

1. Code......... Ward Date.

2. Age ........(years); sex: $\square$ 1. Male $\square$ 2. Female; body weight . $\mathrm{Kg})$; height............

3. The type of time during anesthesia: $\square$ 0. Day (0730-1530) $\square$ 1. Evening/night (1531-0729)

4. ASA physical status classifications: $\square$ 1. Class1 E $\square 2$ Class.2 E $\square$ 3. Class 3 E $\square$ 4. Class 4 E $\square$ 5. Class $5 \mathrm{E} \square$ 6. Class $6 \mathrm{E}$

5. Anesthetic duration time (minutes)

6. Personal history:

$\square$ 1. Previous anesthesia $\square$ 2. Smoking ( $\geq 10$ packs per year) $\square$ 3.Alcoholic

$\square$ 4. Allergy history: $\square$ 0. No $\square$ 1. Antibiotic $\square$ 2. Narcotic $\square$ 3. Others. .

$\square$ 5. Using the addictive substance: $\square$ 0. No $\square$ 1. Morphine $\square$ 2. Fentanyl $\square$ 3. Others

$\square$ 6. No history

7. The anatomic site of operation

$\square$ 1. Intracranial $\square$ 2. Intra-abdominal $\square$ 3. Intrathoracic $\square$ 4. Cardiac $\square$ 5. Others

8. The operation procedure:

9. Preoperative comorbidities

$\square$ 0. Normal

$\square$ 1. Abnormal risks:

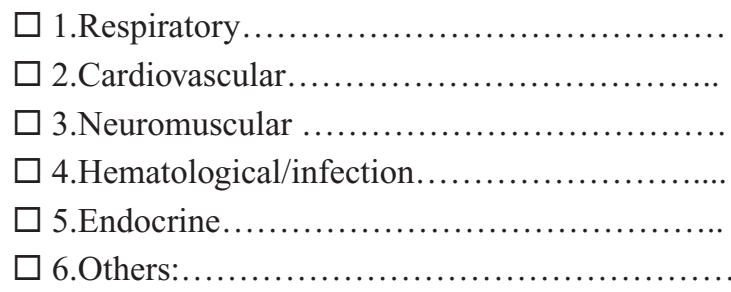

10. Current medications: $\square$ 1.Antihypertensive $\square$ 2. Hypoglycemic drugs $\square$ 3. Bronchodilator

$\square$ 5. Steroids (within one year) $\square$ 6. Anticoagulant (within 7 days) $\square$ 7. NSAID including aspirin

$\square$ 8. Others

11. Main anesthetic technique $\square$ 1. GA $\square$ 2. GA (TIVA) $\square$ 3. Others

12. Monitoring: $\square$ 1. NIBP $\square$ 2. Invasive $\mathrm{BP} \square$ 3. $\mathrm{SpO}_{2} \square$ 4. Temperature $\square$ 5. CVP

$\square$ 6. Peripheral nerve stimulator $\square$ 7. PAP $\square$ 8. $\mathrm{CO} \square$ 9. EKG $\square$ 10. End tidal $\mathrm{CO}_{2}$

$\square$ 11. Etc.gas $\square$ 12.Urine output $\square$ 13. Esophageal stethoscope $\square$ 14. Chest piece

$\square$ 15. Airway pressure $\square$ 16. BIS $\square$ 17. Transesophageal echography (TEE) $\square$ 18. Others...

13. Airway: $\square$ 1. Oro-tracheal tube $\square$ 2. Nasal-tracheal tube $\square$ 3. Tracheostomy $\square$ 4. Others

14. Anesthetic agents

$\square$ 1. Induction agents: $\square$ 1.Thiopental $\square$ 2. Propofal $3 \square$. Ketamine $\square$ 4. Etomidate

$\square$ 5. Midazolame $\square$ 6. Diazepam

2. Muscle relaxant: $\square$ 7. Succinylcholine $\square$ 8. Pancuronium $\square$ 9. Atracurium

$\square$ 10. Cisatracurium $\square$ 11. Vecuronium $\square$ 12. Rocuromium

3. Volatile/inhalation: $\square$ 13. Nitrous oxide $\square$ 14. Halothane $\square$ 15. Isoflurane

$\square$ 16. Sevoflurane $\square$ 17. Desflurane

4. Sedative agents: $\square$ 18. Morphine $\square$ 19. Fentanyl $\square$ 20. Pethidine

$\square$ 5. Analgesic agents: $\square$ 21.Nalbuphine $\square$ 22. lidocaine $\square$ 23. Bupivacaine $\square$ 24. Ropivacaine

$\square$ 25. levobupivacaine (chirocaine) $\square$ 26. Prostignine and atropine 
15. Post-operative admission:

$\square$ 1. RR $\square$ 2. ICU $\square$ 3.Ward $\square$ 4. Dead $\square$ 5. Unplanned ICU admission

16. Patient's complication $\square 0$.No complications $\square$ 1. Intra-operative complications

$\square$ 2. Recovery room complications $\square$ 3. During 24 hours after operation complications

17. The complication in patients with cardiac arrest within 24 hours after anesthesia for an emergency surgery:

Figure SI

Abbreviations: ASA, American Society of Anesthesiologists; E, emergency; NSAID, non-steroidal anti-inflammatory drug; GA, general anesthesia; TIVA, total intravenous anesthesia; NIBP, non-invasive blood pressure; $\mathrm{BP}$, blood pressure; $\mathrm{SpO}_{2}$, pulse oximetry; CVP; central venous pressure; PAP, pulmonary artery pressure; $\mathrm{CO}$, cardiac output; EKG, electrocardiogram; End tidal $\mathrm{CO}_{2}$, end-tidal carbon dioxide; BIS, bispectral index; TEE, transesophageal echography; RR, recovery room; ICU, intensive care unit; CPR, cardiopulmonary resuscitation; ICU, intensive care unit; ROSC, return of spontaneous circulation.

\section{Anesthetic record of cardiac arrest (Form 2)}

1. Time to cardiac arrest (days/month/years)

2. Type of time to cardiac arrest:

$\square$ 1. Working hours (0730-1530) $\square$ 2. Evening/night (1531-0729)

3. Timing of cardiac arrest from surgery (minutes).

4. Location at time of cardiac arrest: $\square$ 0. Outside the operating room (recovery room, ICU, ward, X-ray, and MRI) $\square 1$. In the operating room (OR)

5. Signs/symptoms indicating arrest: $\square 0$. Pulseless (palpation) $\square$. Monitor for indicating arrest

6. Baseline hemodynamic status before cardiac arrest:

$\square$ 1. Normal $\square$ 2. Hypertension $\square$ 3. Shock $\square$ 4. Ischemia /MI

$\square$ 5. Arrhythmias $\square$ 6. Anemia $\square$ 7. Coacgulopathy $\square$ 8. Sepsis

7. Initial events: $\square$ 1. Cardiovascular: $\square$ 1. Lethal arrhythmia $\square$ 2. MI or ischemia

$$
\square \text { 3. Hypotension }
$$

2. Respiratory: $\square$ 1.Respiratory depression metabolic $\square$ 2. Unknown

$\square$ 3. Others.

8. Main causes of arrest: $\square$ 1. Anesthetic cause ........... $\square$ 2. Surgical cause.

$\square$ 3. Patient's cause

9. Initial EKG rhythms: $\square$ 1. VF/VT $\square$ 2. PEA $\square$ 3. Asystole $\square$ 4. Bradycardia $\square$ 5. Others.........

10. Timing to activate $\mathrm{CPR}$ teams (minutes):

11. Timing before onset of CPR after detection of cardiac arrest: (minutes).

12. Defibrillation: $\square$ No $\square$ Yes

13. Time to first defibrillation after detected cardiac arrest (minutes) ............ and first energy for defibrillation (Jules)

14. CPR teams: $\square 0$. Ward teams $\square$ 1. Anesthetic teams

15. All CPR team members trained: $\square 0$. No $\square$ 1. Yes

16. Previous cardiac arrest treatments

$\square$ 1. Mechanical ventilation

$\square$ 2. Drug administration: $\square$ 0. No $\square$ 1. Epinephrine $\square$ 2.Sodium bicarbonate $\square$ 3.Atropine

$\square$ 4. Calcium gluconate

5. Inotropic drug: $\square$ 1.Dopamime $\square$ 2.Dobutamine $\square$ 3.Nitroglycerine

$\square$ 4. Levophed

6. Antiarrhythmic drug: $\square$ 1.Epinephrine $\square$ 2.Primacor $\square$ 3. Amiodarone

17. Resuscitation drug infusion: $\square$ 0. No $\square$ 1.Inotropic drug .......... $\square$ 2.Antiarrhythmic drug............

17.1 Resuscitation inotropic drug infusion: $\square$ 0. No $\square$ 1.Dopamime $\square$ 2.Dobutamine

$\square$ 3. Nitroglycerine $\square$ 4. Levophed

17.2 Resuscitation anti-arrhythmic drugs infusion: $\square$ 0. No $\square$ 1. Epinephrine $\square$ 2. Primacor

3. Amiodarone 
18. Drug treatment of patients during and post-CPR

\begin{tabular}{|c|c|c|c|c|}
\hline \multirow[t]{2}{*}{ drug } & \multirow[t]{2}{*}{ (0 dose) } & \multicolumn{3}{|c|}{ Drug administration } \\
\hline & & I dose & 2 dose & $3 \geq$ dose \\
\hline \multicolumn{5}{|l|}{ Epinephrine } \\
\hline \multicolumn{5}{|l|}{ Atropine } \\
\hline \multicolumn{5}{|l|}{ Ephedrine } \\
\hline \multicolumn{5}{|l|}{ Bicarbonate } \\
\hline \multicolumn{5}{|l|}{ Calcium glucnate } \\
\hline \multicolumn{5}{|l|}{ Lidocaine } \\
\hline \multicolumn{5}{|l|}{ Amiodarone } \\
\hline \multicolumn{5}{|l|}{ Levophed } \\
\hline \multicolumn{5}{|c|}{ Resuscitation infusion drug during CPR } \\
\hline \multicolumn{5}{|c|}{ Inotropic drug: } \\
\hline \multicolumn{5}{|l|}{ Dopamime } \\
\hline \multicolumn{5}{|l|}{ Dobutamine } \\
\hline \multicolumn{5}{|c|}{ Nitroglycerine } \\
\hline \multicolumn{5}{|l|}{ Levophed } \\
\hline \multicolumn{5}{|c|}{ Antiarrhythmic drug: } \\
\hline \multicolumn{5}{|c|}{ Epinephine } \\
\hline \multicolumn{5}{|l|}{ Primacor } \\
\hline \multicolumn{5}{|l|}{ Amiodarone } \\
\hline \multicolumn{5}{|c|}{ Drug infusion in post-CPR } \\
\hline \multicolumn{5}{|c|}{ Inotropic drug: } \\
\hline \multicolumn{5}{|l|}{ Dopamime } \\
\hline \multicolumn{5}{|l|}{ Dobutamine } \\
\hline \multicolumn{5}{|l|}{ Nitroglycerine } \\
\hline \multicolumn{5}{|l|}{ Levophed } \\
\hline \multicolumn{5}{|c|}{ Antiarrhythmic drug: } \\
\hline \multicolumn{5}{|c|}{ Epinephine } \\
\hline \multicolumn{5}{|l|}{ Primacor } \\
\hline Amiodarone & & & & \\
\hline
\end{tabular}

19. Estimated blood loss.... $\mathrm{mL}$

20. Total volume replacement before arrest

$\square$ 1. Crystalloids $\mathrm{mL}: \square$ 1. NSS $\mathrm{mL} \square 2$. LRS $\mathrm{mL} \square$ Acetar $\mathrm{mL}$ $\square$ Orther

2. Colloid $\mathrm{mL} \square:$ 1. Haemaccel ... $\mathrm{mL} \square$ 2. Haesterile ...... mL $\square$ 3. Voluvent...... mL $\square$ 4. Orther ...... mL

3. No

21. Total blood replacement before arrest:

$\square$ 0. No $\square$ 1. Whole blood... .. mL $\square$ 2. PRC .... $\mathrm{mL} \square$ 3. FFP..... mL $\square$ 4. Plt........ mL

5. Other blood products $\mathrm{mL}$

22. Intraoperative body temperature monitoring: $\square$ 1. No $\square 2$. Yes

23. Duration time of CPR (minutes).

24. Results of CPR: $\square 0$. Never achieved ROSC $\square$ 1. Returned of spontaneous circulation

25. Post-CPR admition unit:

$\square$ 1. RR $\square$ 2. ICU $\square$ 3.Ward $\square$ 4, Dead in OR $\square$ 5.Unexpected admit ICU

26. Surgery duration time (minutes).................

27. Time to event (hours) of post-CPR outcomes (24 hours-one month)

$\square$ 1. Death time (minutes). $\square$ 2. Complete recovery time (minutes)

$\square$ 3. Recovery with complications time (minutes).

Remarkable: the patient achieved return of spontaneous circulation (ROSC), researchers followed up for one month. 
28. The period time of complications occurrence $\square$ 1. Immediate outcomes of post-CPR (within 24 hours) $\square 2$. Shortterm outcomes of post-CPR ( $>24$ hours -7 days of post-CPR) $\square$ 3. Long-term outcomes of post-CPR ( $>7$ days -1 month of post-CPR outcomes.

\begin{tabular}{|c|c|c|c|}
\hline Complications of post-CPR patients & Within 24 hours & $>24$ hours-7 days & $>7$ days -1 month \\
\hline \multicolumn{4}{|l|}{ Respiratory complications: } \\
\hline \multicolumn{4}{|l|}{ I. Restrictive lung disease } \\
\hline \multicolumn{4}{|c|}{ 2. Prolong on endothacheal tube (days) } \\
\hline \multicolumn{4}{|c|}{ 3. Respiratory failure } \\
\hline \multicolumn{4}{|l|}{ 4. Lower respiratory infection } \\
\hline \multicolumn{4}{|l|}{ 5. $\mathrm{SpO}_{2}<90 \%$ (desaturation) } \\
\hline \multicolumn{4}{|l|}{6 Prolonged ventilator support (days) } \\
\hline \multicolumn{4}{|l|}{ 7. Others .................. } \\
\hline \multicolumn{4}{|l|}{ Cardiovascular/ hemodynamic status: } \\
\hline \multicolumn{4}{|l|}{ I. Hypertention } \\
\hline \multicolumn{4}{|l|}{ 2. Shock } \\
\hline \multicolumn{4}{|l|}{ 3. Ischemia /MI } \\
\hline \multicolumn{4}{|l|}{ 4. Arrhythmias } \\
\hline \multicolumn{4}{|l|}{ 5. Vascular HD } \\
\hline \multicolumn{4}{|l|}{ 6. $\mathrm{CHF}$} \\
\hline \multicolumn{4}{|l|}{ 7. Others ................... } \\
\hline \multicolumn{4}{|l|}{ Neuromuscular complications } \\
\hline \multicolumn{4}{|l|}{ I. Vegetative/brain death } \\
\hline \multicolumn{4}{|l|}{ 2. Alteration of consciousness } \\
\hline \multicolumn{4}{|l|}{ 3. Spinal cord injury/disease } \\
\hline \multicolumn{4}{|l|}{ 4. Neuropathy/myopathy } \\
\hline \multicolumn{4}{|l|}{ 5. Increase ICP } \\
\hline \multicolumn{4}{|l|}{ 6. Previous CVA/TIA/ Stroke } \\
\hline \multicolumn{4}{|l|}{ 7. Convulsion } \\
\hline \multicolumn{4}{|l|}{ 8. Others......... } \\
\hline \multicolumn{4}{|l|}{ Hematology/infection: } \\
\hline I. Anemia & & & \\
\hline 2. Coacgulopathy & & & \\
\hline 3. Others........................... & & & \\
\hline Endocrine/metabolic: & & & \\
\hline I. DM & & & \\
\hline 2. Eectrolyte/acid-base imbalanced & & & \\
\hline 3. Hyperthyroid & & & \\
\hline 4. Others............................. & & & \\
\hline Others: & & & \\
\hline I. Sepsis & & & \\
\hline 2. Renal impairment & & & \\
\hline 3. Renal failure & & & \\
\hline 4. Ascites & & & \\
\hline 5. Bowel ischemic & & & \\
\hline 6. Fever & & & \\
\hline 7. Bowel obstruction & & & \\
\hline
\end{tabular}

29. Suggested corrective strategies

$\square$ 1. Guideline practice $\square$ 2.Additional training $\square$ 3. More man power $\square$ 4. Improved supervision

$\square$ 5. Improved communication $\square$ 6. Equipment maintenance

$\square$ 7. Quality assurance activity $\square$ 8. Good referral system $\square$ 9. Others

Figure S2

Abbreviations: OR, operating room; RR, recovery room; ICU, intensive care unit; MRI, magnetic resonance imaging; MI, myocardial infarction; EKG, electrocardiogram; VF, ventricular fibrillation; VT, ventricular tachycardia; PEA, pulseless electrical activity; CPR, cardiopulmonary resuscitation; ROSC, return of spontaneous circulation; NSS, normal saline $(0.9 \% \mathrm{NaCl})$; LRS, lactated ringer's solution; PRC, pack red cell; FFP, fresh frozen plasma; Plt, platelets; $\mathrm{SpO}_{2}$, pulse oximetry; HD, heart disease; CHF, congestive heart failure; ICP, intracranial pressure; CVA, cerebrovascular accident; TIA, transient ischemic attack; DM, diabetes mellitus; CPR, cardiopulmonary resuscitation. 
Risk Management and Healthcare Policy

Dovepress

\section{Publish your work in this journal}

Risk Management and Healthcare Policy is an international, peerreviewed, open access journal focusing on all aspects of public health, policy, and preventative measures to promote good health and improve morbidity and mortality in the population. The journal welcomes submitted papers covering original research, basic science, clinical \& epidemio-

logical studies, reviews and evaluations, guidelines, expert opinion and commentary, case reports and extended reports. The manuscript management system is completely online and includes a very quick and fair peerreview system, which is all easy to use. Visit http://www.dovepress.com/ testimonials.php to read real quotes from published authors.

Submit your manuscript here: http://www.dovepress.com/risk-management-and-healthcare-policy-journal 